\title{
THE SOCIOLOGICAL APPROACH TO CRIME AND CORRECTION
}

\author{
DANIEL Glaser*
}

The approach to crime which is distinctively saciological assumes that the criminal acquires his interest, ability, and means of self-justification in crime through his relationship to others. This conception contrasts sharply with those psychoanalytic and biological approaches which conceive of crime as the expression of innate impulses which the criminal has not learned to control. ${ }^{1}$ It will be noted, however, that in recent years, the sociological conception has been largely accepted by many persons identified with disciplines other than sociology.

\section{I}

\section{The Early Cultural Emphasis}

The early divergence of sociological and psychological approaches to crime probably stems in part from the fact that criminals and delinquents were referred as separate individuals, to psychiatrists and psychologists, from whom diagnoses and prognoses were requested. Also, these specialists were likely to receive a disproportionate number of offenders who exhibited emotional instability or other psychological defect. In contrast, sociologists first studied crime as a statistical phenomenon, comparing the total arrest or conviction rates of different countries, cities, neighborhoods, occupations, races, social classes, and other collective units. The sociologist's problem was to explain the differences which he found in such group rates. The cases brought to his attention consisted of all persons who had official crime or delinquency records.

To the sociologist, all intergroup differences in behavior patterns were understandable only if seen as consequences of the cultures in which individuals are reared. A culture, however, was seen as understandable only in terms of its history, which antedates any single individual. To oversimplify slightly, one might say that the sociologist explained the prevalence of criminal behavior in one group and noncriminal behavior in another in the same way in which he would explain the fact that people reared in Paris talk French and people reared in Omaha talk English.

Space does not permit detailed review of nineteenth and early twentieth century European writings which foreshadowed this culture determinism approach. It may suffice to point out that some writings of this period which were called "sociology,"

- B.A. 1939, M.A. 1947, Ph.D. I954, University of Chicago. Associate Professor of Sociology, University of Illinois. Prisons Officer, U. S. Military Government in Germany, 1946-49; Sociologist-Actuary, Illinois Parole and Pardon Board, 1950-54. Contributor to sociological and correctional publications.

${ }^{2}$ Cf. August Aichrorn, Wayward Youth 4 (1935); Michaels, Delinquency and Control, 24 AM. J. ORthopsYChIATRY 258 (1954). 
like those of the Italian journalist Enrico Ferri, were not very sociological. On the other hand, the works of the French psychologist and magistrate Gabriel Tarde contained much which closely resembled the criminological writings of American sociologists forty years later.

The cultural emphasis achieved its major influence in the second quarter of the twentieth century. Its leading protagonist was the late Clifford $\mathrm{R}$. Shaw, whose constant collaborator was Henry D. McKay. Their contributions were a series of statistical studies and case histories of delinquency in Chicago. ${ }^{2}$ Among their principal findings, which have stood the test of time fairly well, were: ( $\mathrm{I}$ ) delinquency is concentrated in deteriorated slums located in those portions of a city which once were residential, but are changing to commercial and industrial districts; (2) these areas always have the highest delinquency rates, even after their population changes almost completely in national descent or race; (3) organized vice, political corruption, and most other social problems are concentrated in these areas, and case study analysis indicates that this is because social control breaks down there owing to the low social status of the residents, their newness to the urban scene, and the unattractiveness of the area for new residential investment and development; (4) as residents of these areas move elsewhere in the city, the delinquency rates of their children decrease; (5) delinquents from the high-delinquency areas have higher recidivism rates than other delinquents; (6) delinquency is usually group behavior from the outset and becomes group behavior to a greater extent as youth become more advanced in delinquency (they found that only 11.8 per cent of delinquents known to the juvenile court and only 6.9 per cent of all juvenile stealing cases were cases of lone delinquency); and (7) gangs are traditional in the streets of the high-delinquency areas, and youth are enculturated into delinquency in the normal course of growing up in these areas.

Shaw's approach to the study of delinquency was extended through similar research by others. Notable was F. M. Thrasher's investigation of $\mathrm{I}_{3} \mathrm{r} 3$ boys' gangs in Chicago, in which he traced the manner in which spontaneous children's play groups in the slums become transformed into unified criminal gangs through exciting disapproval and, therefore, becoming collectively involved in conflict with other gangs, police, and other adults. ${ }^{3}$ It was shown that in the slum, the gang successfully competes with legitimate agencies to meet fundamental needs of youth for recognition, excitement, affection, and loyalty. Also, services of the gang to politicians, dealers in stolen goods, and organized vice and crime syndicates were shown to cause these agencies to reciprocate by helping the gang in resisting its enemies and by providing career opportunities for its leaders. While Chicago was

2Chifford R. Shaw \& Henry D. McKay, Delinguency Areas (r929), The Jackroller (1930), Naturae fistory of a Delinguent Career (i93i), Social Factors in Juvenile Delinquenci, published as 2 U. S. Nat'l Comm'n on Law Observance and Enforcenent, Report on the Causes of Crime (ig3Y), Brothers in Crime (1938)...

${ }^{3}$ F. M. Thrasher, The Gang (2d ed. 1936). 
the center for the Shaw-MacKay-Thrasher-type of research, it also was carried on in at least twenty other cities, with largely similar findings. ${ }^{4}$

This picture of the slum youth learning crime, as children in other cultural communities learn good manners and legitimate ambitions, through enculturation, also was extended to explain the behavior of adult professional criminals. The late Edwin $\mathrm{H}$. Sutherland, dean of American criminologists, annotated and published in 1937 a professional thief's account of his profession..$^{5}$ It showed how members of this profession gradually acquire a complex of highly-specialized techniques, including skill in planning offenses, verbal abilities for dealing with victims and with the law, knowledge of how to dispose of stolen goods, and, if detected, the ability to "fix" a case by dealings with the police, court officials, and victims. Such knowledge is acquired only through association and cooperation with thieves, much of the former occurring in jails and prisons. As the thief becomes sophisticated in these professional techniques, he acquires an honorific status and looks down on more amateur offenders. Like a member of any other profession, he shares the esprit de corps of the profession and incorporates into his own thinking his profession's consensus of values. He thus lives in a somewhat distinct cultural world, insulated from opposing values in the larger societies.

One final work might be mentioned, a highly influential criminology textbook, Crime and the Community, which was written by a Columbia University Professor of Latin American History, Frank Tannenbaum, assisted by Magistrate Morris Ploscowe, John Dewey, and others, including inmates of New York state prisons. ${ }^{8}$ The literary skills of these authors enabled them to describe this process of enculturation in a much more vivid style than that usually found in sociologists' writings. The introduction to criminal careers was ascribed to "the dramatization of evil" in the arrest, jailing, and trial experience of the first offender. The procedures involved here were described as tagging the individual as a criminal, emotionally rejecting him from respectable society, and making the company of other delinquents or criminals the sole place where he can find acceptance, solace, encouragement, and even prestige. Subsequent experience is described as habituation to crime as a way of life; it becomes normal activity for the criminal and has a variety of supporting influences. Further experience with law enforcement agencies is portrayed as a "hardening process," the ultimate result of which is the "warrior psychosis" of the professional criminal. The latter is seen as motivated by fear and by a philosophy

'Cf. Clifford R. Shaw \& Henry D. Mcisay, Juvenile Delinquency and Urban Areas (r942). A notable, but little publicized, outgrowth of this research is the shift in delinquency prevention from childguidance clinics and settlement houses to "corner workers," "detached social group workers," slum resident committees, and "reaching out" (or "aggressive") social work. The latter locate and work with delinquents and gangs, even in the face of resistance initially, rather than waiting for them to seek counsel or aid. This approach was pioneered and still is being led, in many respects, by Shaw's Chicago Area Projects.

${ }^{E}$ Edwin H. Sutherland, The Professional Thef (1937).

- Frank Tannenbaum, Crime and the Community (1938). 
which sees all life as a racket and which thereby justifies any means to the end of self-preservation.

\section{II \\ The Great Debates}

The almost exclusive reliance of sociologists on enculturation as an explanation for delinquency and crime during the second quarter of this century involved them in frequently bitter debates with psychologists, psychiatrists, and biologists, as well as with legal and theological writers.

Sutherland's Principles of Criminology, which first appeared in 1924 and which, in its successive editions, has been by far the most successful text in criminology, from the outset criticized "psychopathy" as an etiological concept. Sutherland pointed out that some psychiatrists diagnosed almost all criminals as psychopaths, making the two terms virtually synonymous, while others used it for only a small percentage of criminals. In any case, Sutherland contended, psychopathy was too vague a concept for useful diagnosis, and if it were used as synonymous with certain patterns of criminality, it still left these patterns to be explained. His implication was that these patterns of criminality, like others, were mainly "the result of social interactions," an interpretation consistent with much current psychiatric theory, but in contradiction to the constitutional explanation of psychopathy then implicit or explicit in most use of this term.

Sociologists also attacked other psychological explanations for criminality, particularly low intelligence and personality. This offensive reached a high point in I950, when two of Sutherland's students, Karl F. Schuessler and Donald R. Cressey, reviewed II3 attempts to differentiate criminals from noncriminals by means of personality tests. ${ }^{7}$ They found that only forty-two per cent of these efforts yielded significant differentiations between average scores, but the deviation from the average among both the criminals and the noncriminals created so much overlap as to make none of these tests adequate for diagnosis or prediction of criminality. Furthermore, differences in education and social class between the criminal and the control groups tested, as well as the effects of imprisonment on the criminals studied (who usually were prison inmates), might account for most of the differences found in their test responses.

During this period, the enculturation explanation for crime also led many sociologists to ally themselves with psychiatrists in war against classical legalists and fundamentalist religious leaders on the free-will versus determinism issue. To this writer, this conflict seems to be a "phony war" in which the combatants disagree not in their conception of human behavior so much as in their taste regarding usage of the words "free-will" and "determinism." In their polemical zeal, however, each side misrepresents both its own and its opponents' conceptions (a common feature of arguments). The determinists, contrary to implications conveyed in the

\footnotetext{
${ }^{7}$ Schuessier \& Cressey, Personality Characteristics of Criminals, 55 AM. J. SocioLocY 476 (1950).
} 
debate, recognize that humans experience awareness of alternative possible courses of behavior and make deliberate choices between those alternatives which they perceive. And the free-will exponents, in spite of assertion in argument, recognize that the course of a human's behavior is a function of the perceptions which he has hadwhich is why they are so concerned that children receive "correct" teaching and preaching.

The determinist position results from the metaphysical view of the world as "interconnected," which underlies any scientific explanation for events. The freewill position grows out of different metaphysical foundations, stressing the autonomy rather than the connectedness of certain components of the universe-a stress necessary for ethical or theological evaluation of behavior. Increasingly, however, the use of different frames of reference for different types of problem is accepted in science and philosophy. ${ }^{8}$ The free-will versus determinism debate seems likely to lose its intensity from this increasing awareness of the influence of conceptual frameworks on thought, from declining interest in metaphysical issues, and from the growing interests of sociologists, psychologists, and psychiatrists in voluntaristic rather than reflexive conceptions of human behavior.

The "great debates" between sociology and psychology have lost some of their former fervor. The disputes ultimately led to concessions on both sides, or more accurately, to reformulations on both sides. Sociologists succeeded impressively well in discrediting monopolistic claims of other disciplines to a single simple explanation for crime. They have, however, been less successful in formulating a single general explanation for crime on which they could agree.

III

\section{EFForTs at INTEGRATION}

Perhaps the most telling criticism which sociologists encountered in defending enculturation explanations for crime was the failure of these explanations to account for the nondelinquents in high-delinquency areas. Sociologists were inclined to dismiss this by asserting that most of these simply were delinquents who had never been caught. Sociologists employed on delinquency prevention programs in highdelinquency areas, however, became increasingly aware of the conflict of criminal and noncriminal values in the culture to which any youth is exposed. ${ }^{10}$ Sociologists employed in prisons and parole systems were impressed with the noncriminal ties of many offenders. This impression is even gained to an extent not warranted by the facts, because prisoners are motivated to convey a noncriminal picture of themselves to the treatment staff. The study of white-collar crime and surveys of un-

\footnotetext{
${ }^{8}$ John Dewey \& A. F. Bentley, Knowing and the Known (i949); James B. Conant, Modern SCIENCE AND MODERN MAN (I952).

'The most up-to-date summary of sociological criticism in criminology is GeORge B. Vold, TheoRETICAL Crisinologr (I958). A more brief and abstract critique of theoretical models in criminology is provided in Glaser, Criminality Thearies and Behavioral Images, 56 AM. J. SoctoLocy 433 (x956).

${ }^{10} \mathrm{Cf}$. Kobrin, The Conflict of Values in Delinquency Areas, I6 AM. Socrologrcal Rev. 635 (195I).
} 
detected crimes admitted by respected persons blurred the distinction which previously characterized the sociological image of a criminal and a noncriminal society within the United States. ${ }^{11}$ Finally, violent crimes committed by individuals clearly not involved in a criminal social world, while small in the total crime rates of the country, were extremely difficult to explain sociologically, received an inordinate amount of attention in public discussion of crime, and were easily interpreted speculatively by a variety of untestable psychoanalytic postulations on unconscious symbolism.

One mode of reaction to these shortcomings of enculturation explanations for crime was to assert that all crime is affected by a multiplicity of factors and that different factors are prepotent in different offenses. This solution offered no framework for specifying the exact function of particular factors in separate crimes nor any indication of interrelationship between the factors. Multiple causation was accepted by criminologists of diverse academic background, and this made it appear to the more casual student that they all were agreed. Each of the exponents of multiple causation, however, continued to emphasize his previous pet theory. The sociologists stressed culture, and the psychologists, personality, while scattered other writers emphasized biological or other interpretations, although all piously generalized on multiple causation.

A foreshadowing of a more general explanation for crime, to replace both multiple-factor and simple enculturation interpretations, was provided by Sutherland's "differential association" theory. ${ }^{12}$ As the editors of his posthumous papers indicate, Sutherland conceived of this theory as tentative, "subject to revision in the light of criticism and research." ${ }^{.13}$ He revised it in several respects before his death, and its further development and refinement still is going on.

Slightly paraphrased, Sutherland's last formulation of his theory is as follows: Criminal behavior is learned in interaction with others, principally in intimate per-

${ }^{11}$ Cf. Newman, White Collar Crime, infra 735. Porterfield, Delinquency and lts Dutcome in Court and College, 49 AM. J. Socrology 199 (r943); Wallerstein \& Wyle, Our Law-Abiding Law-Breakers, 25 Probatton ro7 (1947); E. H. Sutherland, White Coliar Crime (1949). "White-collar crime" refers to violation of law by respected persons as a routinely accepted feature of prevailing business (e.g., misrepresentation in selling and collusion to reduce competition). Sociologists have debated heatedly the propriety of including white-collar crime in the basic subject matter of criminology. To the writer, however, this is an issue not meriting such controversy, since all boundaries of study should be fexible. Attention to white-collar crime makes a criminologist alert to the continuity between the attitudes toward law of persons called "criminal" and persons generally respected as though noncriminal. The fact that criminal prosecution rarely occurs in white-collar crime, however, makes its social consequences and" interpretation necessarily somewhat different from ordinary crime, particularly felonics, and justifics some specialization in studying the latter. In this article, the writer's primary concern is with the most commonly prosecuted felony-type offenses. Arguments for including white-collar crime in criminology are presented in Hartung, White-Collar Offenses in the Wholesale Meat Indistry in Detroit, 56 As. J. Socrology 25 (1950), with critical comment by E. W. Burgess and rejoinder by Hartung. Counterargument is found in Tappan, Who Is the Criminal?, I2 Am. Socrozocronz Rev. 96 (1947), and Crime and the Criminal, Fed. Prob., July-Sept. 1947, p. 41; Caldwell, $A$ Re-examination of the Concept of White-Collar Crime, Fed. Prob., March 1958, p. 3.

12 First set forth in Edwin H. Sutherland, Principles of Criminology 5-7 (3d ed. 1939).

${ }^{23}$ Albert Cohen, Alfred Lindesmith, \& Kari Schuessler (Eds.), The Sutherland Papers 6 (1956). 
sonal groups. That which is learned includes techniques, attitudes, and rationalizations. Whether a person's motives and drives are criminal or noncriminal is a function of whether the legal codes have been defined by those around him in a manner favorable to their observance or to their violation. Most people encounter a mixture of these two types of influence. A person will become criminal if his associations result in an excess of definitions favorable to violation of law over definitions unfavorable to violation of law. The influence of such differential association is a function of its frequency, duration, priority, and intensity, in one direction or another. Both criminal and noncriminal behavior is acquired in such association by the same learning mechanisms, and both satisfy the same general human needs and values; but differential association determines the extent to which a person's experience promotes learning and motivation by criminal rather than noncriminal influences.

Sutherland seems to have formulated this theory as a way in which the many actual and alleged correlates of crime, such as poverty, family conflicts, personality disturbance, and slum residence, could be causally related to crime. These conditions, to be factors in the criminality of an individual, must so affect his social relationships as to promote his being influenced by criminals and restrict the influence of noncriminal persons on him. Attention to the social relationships of each person studied, however, would also explain why such correlates of crime as family conflict and poverty also may, in some cases, support noncriminal ambitions. From the standpoint of Sutherland's theory, any correlate of crime must be shown to affect an individual's learning experience if it is to be thought of as having a causative function in his criminality. Sutherland's critics generally overlook this integrating function of his theory and the broad sense in which he uses the phrase "differential association." They misrepresent him when they suggest that he predicted that criminality would result with mechanical certainty in any individual whose contacts with criminals exceed contacts with noncriminals.

Essentially, Sutherland set forth a broad point of view for approaching an understanding of criminals, rather than a simple formula for predicting crime. In modern social-psychological terms, what he seems to have had in mind might more aptly be labeled "differential identification," "differential reference," or even "differential learning." It involves a conception of crime as a subclass of the totality of all deliberate human action, as something to be explained as other so-called "voluntary" behavior is explained. It is based on a social-psychological conception of deliberate action as guided by the actors in accordance with the way in which they have learned to rationalize their actions. Such an approach to understanding behavior is convergent with many developments in psychology and sociology. It is a deterministic conception of crime, since it ascribes a person's anticipations to his learning experience; yet, it is consistent with the legal conception of crime as wilful, for it focuses on decision-making as a phenomenon to be studied. This approach contrasts sharply with explanations for crime in terms of biological drives, uncon- 
scious motivation, or pressure of external forces, since such explanations do not as completely trace the connection between the alleged causes and specific, consciouslydirected criminal acts. ${ }^{14}$

Sutherland presented his theory in highly abstract form and apart from its illustration. His illustrative chapters on "processes in criminal behavior" and "behavior systems in crime" cogently described the ways in which professional criminals become enculturated in crime, but he did not illustrate the influence of associations opposing crime. This neglect probably reflects the fact that it has been much easier to study criminals than noncriminals, for criminals may be studied conveniently when they are in custody or under supervision. Noncriminals are more difficult to study, as a rule, and ex-criminals are most difficult (for they seek to hide their past); yet, studying these people may be essential for a more useful understanding of crime. Thus, the most available applications of Sutherland's theory make it appear to be merely the old enculturation explanation for crime, even though its abstract formulation suggests that it might also be a frame of reference for theoretically connecting correlated conditions with specific crimes and for the analysis of noncriminal behavior and correctional processes.

\section{IV}

\section{Recent Theoretical Emphasis}

No more adequate general theory of crime causation has replaced differential association. Several recent developments, however, suggest some of the ways in which such a theory would modify the heritage from Sutherland. The criminology which now seems to be emerging in sociology is one focused on change and operating with a more complex conception of the criminal than that involved in earlier theories. These developments reflect long-term trends in general sociological theory, and they are convergent with some new emphases in the other behavioral sciences. Notable among these trends are: (I) attention to all reference groups-not just membership groups-in tracing social influences on individual behavior; (2) the interpretation of motivation as the way in which a person's representation of the behavioral alternatives which he perceives affects his self-conception and his anticipations; and (3) the analysis of cultural differentiation in a structural-functional frame of reference.

By "reference groups," we designate any persons or groups from whose standpoint an individual evaluates himself and others. These include both groups in which he is a member and groups to which he does not belong, but to which he aspires, or which, for other reasons, provide the standpoint from which he views his own situation. The enculturation approach to crime grew out of the study of the influence of groups on the behavior of their members. Reference-group theory helps to account for much of the behavior of individuals who deviate from the expecta-

\footnotetext{
14 Cf. Glaser, supra note 9; George M. Kelly, The Psychology or Personal Constructs (1955);
} A. R. Lindesmith \& Anselm Strauss, Social Psychology (2d ed. 1956). 
tions of their membership groups, for this theory focuses our attention on all of the groups to which these individuals are oriented. The general conditions under which a person is most likely to evaluate his behavior from the standpoint of groups to which he does not belong include: (I) when the other groups have higher status than his own group; (2) when he is an isolate or a failure in his own group; or (3) when change in group affliation is not strongly counter to the traditions of his society. ${ }^{15}$

While the term "reference group" is fairly new and the analysis of behavior by tracing the influence both of membership and nonmembership groups receives more emphasis now than formerly, such a common-sense idea is by no means completely new. Early students of the gang, while centering their attention on the influence of that group, also noted that most juvenile delinquents drifted out of gang affliations and became law-abiding members of society in late adolescence and young adulthood if they became interested in marriage or acquired steady employment. The latter interests involve change of reference from their peers exclusively to older persons of legitimate professions and to stable family members. ${ }^{16}$ The Tannenbaum and Sutherland enculturation analyses were significant in showing how the transition from enculturation in delinquent gangs to identification with conventional groups becomes unlikely when extensive involvement in criminal groups alienates a youth from conventional circles and increases his ties with professional criminals. Unfortunately, the effects of being caught and prosecuted may be to make criminals the only group to which a youth will aspire. But the task of corrections may be said to be the promotion of noncriminal reference groups; a prisoner is rehabilitated when this promotion is successful.

The study of the nondelinquent in high-delinquency areas has been undertaken on an extensive basis in recent years by persons of diverse academic background. The outstanding finding, expressed in general terms, is that the youth who avoids extreme enculturation in delinquency, despite extensive contact with delinquents, generally is the youth who maintains strong bonds with a noncriminal family. Reckless sees the influence of noncriminal figures as giving such a youth a conception of himself as "good" which "insulates" him from all situations in which he may be encouraged to be delinquent. ${ }^{17}$ This is consistent with psychoanalytic interpretation: the family gives the boy a strong conventional superego-that is, conscience. The problem for criminological theory is to handle adequately the fact that everyone in our society is exposed to multiple influences, some making for criminality and

${ }^{16}$ Cf. Robert K. Merton, Social Theory and Social Structure cc. 9 and yo (2d ed. 1957); Turner, Role-taking, Role-standpoint and Reference Group Behavior, 61 AM. J. SocroLocy 316 (1956), zeprinted in L. A. COSER \& B. Rosenberg, Soctologicai TheORY 272 (1957).

${ }^{10}$ Cf. W. F. Whyte, Street Corner Soctety (I943).

${ }^{17}$ Cf. Reckless, Dinitz, \& Kay, The Self Component in Potential Delinquency and Potential NonDelinquency, 22 Am. Sociological Rev. 566 (1957); S. \& E. Giueck, UnRaveling Juventle Delinguenct 28x (1950). One of the most sophisticated analyses of the extent of family influence on delinquency is Jackson Toby's statistical analysis of court and census data, The Differential Impact of Family Disorganization, 22 A.s. Sociological REv. 505 (I957). 
some making for conventionality, some from membership groups and some from perceived groups in which one is not a fully-accepted member. An understanding of behavior change, from noncriminal to criminal and viceversa, requires a theory of behavior which accounts for human inconsistency and, therefore, permits some prediction and control of the range of this inconsistency.

Several preliminary explorations and formulations of a theory of behavior change and inconsistency have been undertaken by sociologists in terms of analysis of motivation and decision-making in individual behavior. One of Sutherland's students, Cressey, posed a crucial problem for differential association theory: How does one explain the conduct of persons who reach adulthood as highly conventional persons and, therefore, are placed in positions of financial trust, but suddenly violate such trust by embezzlement? Cressey's interviews with 133 embezzlers and his examination of life histories on over 200 other cases of embezzlement led him to an explanation which seemed to fit every case. ${ }^{18}$ He found, first, that trusted persons committed embezzlement only when faced by a financial problem which they could not divulge to others. Nevertheless, he found that in spite of need and opportunity for the crime, the offense was never committed until the embezzler had developed a rationalization which legitimated the offense to him. When frustrated humans perceive a solution to their problems, they seem unable to grasp the solution until they can represent it to themselves in such a manner as to permit them to maintain a favorable conception of themselves. In Cressey's cases, differential association in terms of membership affiliations rarely seemed to explain this reinterpretation of criminal behavior. A shift of perspective, often by taking the standpoint of new reference groups, was needed to change the trustworthy person into an embezzler.

In view of the evidence that most delinquent youth have some acceptance of conventional values, Gresham M. Sykes and David Matza suggest that delinquents must "neutralize" their conventional ties and moral scruples before they can commit delinquency. ${ }^{19}$ They illustrate as common "techniques of neutralization" a variety of rationalizations, such as blaming the theft on pressures from bad parents or on misfortune, defining the victim as a worthless person who deserves to be victimized, justifying the offense in terms of loyalty to a friend, or noting the faults of those who condemn the delinquency. The process of rationalization reconciles crime or delinquency with conventionality; it permits a person to maintain a favorable conception of himself, while acting in ways which others see as inconsistent with a favorable self-conception. In this analysis of motivation by the verbal representation of the world with which a person justifies his behavior, sociologists are con-

${ }^{28}$ Donald R. Cressey, Other People's Money (1953).

${ }^{10}$ Sykes \& Matza, Techniques of Neutsalization: $A$ Theory of Delinquency, 22 AM. Socrolocical Rev. 664 (1957). These authors, unfortunately, neglect the influence of delinquent subcultures in transmitting and reinforcing these very techniques of neutralization which permit delinquents to adhere simultaneously to delinquent and nondelinquent cultures. Thus, these authors may exaggerate the incompatibility of their views with those propounded in Azbert K. Cohen, Delinguent Boys: The Culture of the Gano (I955). 
verging with many psychologists. ${ }^{20}$ This seems to be individualistic analysis of behavior, but the so-called "symbolic interactionists" viewpoint is gaining acceptance, and its sees individual human thought as essentially a social interaction process: the individual "talks to himself" in thinking and reacts to his own words and gestures in "working himself" into an emotional state in much the same manner as he does in discussion or in emotional interaction with others. ${ }^{21}$

Simultaneously with such reconceptualization of individual mental processes in crime, sociologists at midcentury tried to formulate theories of cultural change which would account for the development of criminal and delinquent subcultures within the predominant culture of a society. Some criminology textbooks, notably that of Donald R. Taft, attacked this problem by tabulating every feature of American culture which appeared to be conducive to crime. The features stressed included materialism, impersonal social relations, loyalty to restricted groups, survival of frontier values, and lack of objectivity in viewing crime. ${ }^{22}$

A more abstract way of analyzing social and cultural differentiation has been growing in anthropology and sociology. It is known as the "structural-functional approach," its adherents often are called "functionalists," and it is applied to any aspect of the culture of any society. This whole approach, which is related to functionalism in legal theory, cannot adequately be summarized here, but it may be well to discuss some of the systematic theorizing relevant to crime set forth by Professor Robert K. Merton, of Columbia University, a leading functionalist theoretician and one of the world's foremost sociologists. ${ }^{23}$

Merton revived the term anomie as a designation for the condition of weakened cultural regulation of behavior. Anomie is conceived as developing whenever people are long frustrated in pursuing culturally-prescribed goals by culturallyapproved means. Merton suggested that four types of deviant behavior are likely to develop from anomie, briefly as follows: ${ }^{24}$

I. Innovation involves preserving the culturally-prescribed goals, but deviating from approved means in pursuing these goals. This would explain the disproportionately high rates of property crime in the lower economic classes, especially among those who are educationally and vocationally handicapped and who are in situations of weak social control over the means used to achieve success. Mutual social support by persons sharing these circumstances promotes development of a criminal subculture among them.

\footnotetext{
${ }^{20}$ For psychological formulation, see KeLLY, op. cit. supra note 14. Considerable convergence with the multiple-reference and rationalization analysis of sociologists also is apparent in the psychoanalytic work, Fritz Redl \& David Wineman, Children Who Hate (I95I).

21 Cf. Lindesmith \& Strauss, op. cit. supta note i4; Anselm Strauss, The Social Psychology of George Herbert Mead (1956); George H. Mead, Mind, Self, and Society (1934).

${ }^{22}$ Donald R. Taft, Criminology (3d ed. 1956).

${ }^{23}$ For a general summary of the structural-functional approach, see Merton, op. cit. supra note 15. c. I. The relationship of functionalism in legal theory to functionalism in other fields is set forth briefly in Cohen, Transcendental Nonsense and the Functional Approach, 35 CouUm. L. REv. 809 (r935), reprinted in S. I. Haxakawa (Ed.); Language, Meaning, and Maturity 184 (I954).

${ }^{2}$ MERTON, op. cit. supra note 15, cc. 4 and 5.
} 
2. Ritualism is overconformity to culturally-approved means. This does not normally produce criminals; it produces the person who "never sticks his neck out" where regulations are involved. In a dynamic society with continuously-changing problems in every enterprise, such a rigid person may be destined to an unexpected ceiling in income and may be unable to meet unanticipated problems. It seems to the writer that this description characterizes many of the trusted persons whom Cressey studied who suddenly innovated by embezzlement at a late stage in their careers. Perhaps they were caught in financial dilemmas which they could not divulge and which they did not know how to solve legitimately precisely because their prior life had been so ritualistic.

3. Retreatism is the rejection both of culturally-prescribed goals and of approved means. Chronic vagrants, drunkards, and drug addicts, who make up the bulk of our jail populations, seem to react to anomie by this pattern of deviancy. Finestone has shown how drug addicts develop a subculture which gives them a sense of superiority from their indifference to conventional standards, so that their "kick" is not an "escape," but an achievement in their perception. ${ }^{25}$

4. Rebellion involves partial or complete innovation of goals and means. In juvenile delinquents who still are supported by their parents, so that economic need is not a major motivation to crimes against property, one notes that the goal of independence from conventional authorities becomes a major alternative to conventional success goals. This accounts for the apparently senseless destruction of property by delinquents, their theft of goods which they do not intend to use, and their nonspecialization in deviant behavior (deviancy for deviancy's sake). Cohen has provided us with a brilliant analysis of the development of delinquent subcultures with such norms of deviancy among lower-class male youth who share handicaps in meeting the expectations of our schools. ${ }^{20}$ Unfortunately, this portrayal does not illuminate the transition from rebellious delinquency to professional criminality. Such an extension might result from closer articulation of Cohen's work with Merton's theory and with Sutherland and Tannenbaum's analysis of the professionalization of criminals.

The validity of the foregoing theory will be suggested by the fruitfulness of the research which it stimulates. Systematic research can lead to refinement of the theory and can give the theoretical concepts a more precise empirical reference. Even in their present state of development, however, these concepts seem to the correctional sociologist to be much less vague, much more relevant, and a great deal more testable than the concepts of those correctional psychologists who persist in neglecting the extrafamilial social relationships of criminals.

It is noteworthy that research guided by the types of theorizing described in this part is occurring not so much in criminology as in other areas of sociological study,

${ }^{25}$ Finestone, Cats, Kicks, and Color, 5 Soctal Prozlems 3 (1957); Narcotics and Criminality, 22 Law \& Contemp. Prob. 69 (I957).

${ }^{20}$ Conen, op. cit. supra note 19; see also Toby, Social Disorganization and Stake in' Conformity, 48 J. CRMM. L, C. \& P.S. I2 (1957). 
as well as in psychology and in social and cultural anthropology. Indeed, similarity of theory has resulted in the merger of instruction in these several fields into single departments of "social relations" at Harvard and at Johns Hopkins Universities; elsewhere, these disciplines have joint curricula; and everywhere, they are developing a common literature. Quarrels over proprietary rights to criminology are likely to diminish if the claimants merge into a single behavioral science. And it is the writer's impression that interdisciplinary communication and fusion occurs most successfully when the representatives of the several disciplines collaborate in research on practical problems rather than in discussion of abstract theoretical issues. Such practical research involving sociologists is developing in several fields of law enforcement and corrections.

\section{V}

\section{Sociological Study of the Administration of Justice}

An understanding of change and inconsistency in the behavior of people called criminal is likely to be gained most effectively in conjunction with research on the infuence of prison, parole, and probation, since these are programs designed to change people. Research on such programs, however, necessarily involves the sociologist not only in abstractly explaining criminality, but in analyzing the entire social organization and function of law enforcement, judicial, and correctional agencies. In this connection, sociologists are interested not only in the manifest features of these enterprises, but also in their unofficial practices and unintended consequences.

A general sociology of administrative organization and a sociology of the professions have been growing rapidly in recent decades. Application of the theory and the research techniques developed in these fields to the study of police, court, and prison organization is just beginning. Unfortunately, the police and the courts have been particularly resistant to study, preferring to keep the social relationships and pressures affecting their work out of the picture which the public has of them, and even out of their conscious conception of themselves.

A study by William A. Westley brought out the effects on police behavior of the pressures to make arrests leading to convictions in felony cases. ${ }^{27}$ Interviews indicated that the police see such arrests as the major factor in public esteem of the police and as a primary factor in a policeman's chance for rapid promotion. This leads police to legitimize almost any means to secure felony convictions. Acceptance of illegal use of violence as an interrogation technique was especially supported by the policemen studied, particularly where the arrestees were of low social esteem, such as members of minority groups, vagrants, and, especially, alleged sex offenders. But public reactions to some use of violence leads to a defensiveness among policemen. Even those who did not use illegal violence extensively reported that they

97 Westley, Diolence and the Police, 59 AM. J. Socrology 34 (1953); Secrecy and the Police, 34 SOCIAL Forces 254 (1956). 
would be secretive about violence committed by their colleagues, feeling that any exposure would jeopardize the status of all policemen and would lead to reprisals against them by their colleagues. The research indicates the operation of an informally-communicated and enforced code of behavior in the police profession (as in many professions) which directly contradicts official regulations in many respects. Much of it may also work at cross-purposes with parole, probation, and the courts. More research, already begun, may provide and validate a fuller picture of these unofficial understandings and of the extent to which they are altered by various types of police administration and training.

The sociological study of judicial organization and procedure is now occurring on a more extensive basis than ever. With strong initial impetus from the late Supreme Court Justice Robert H. Jackson, and with considerable financial backing from the Ford Foundation, numerous large-scale research projects have been instituted in the last five years by the American Bar Foundation, the American Law Institute, and several universities. Sociologists are working with lawyers and other specialists in studying the operation of criminal courts and in drafting model legislation to correct the deficiences which they find. Unfortunately, few publications are available yet on the results of these undertakings.

Arthur L. Wood's interviews with over a hundred criminal lawyers and with a like number of civil lawyers provided a picture of the extent to which informal contacts lead to settlement of criminal cases outside the courtroom. ${ }^{28}$ They also indicated the reasons for this situation. It was shown that strains result from the conflict of the adversary system, the necessity for friendship with the prosecution in order to build a criminal law practice, and the fact that criminal clients are to be served, even though they generally are guilty of some offense. The criminal lawyer resolves these strains by trying to provide some service to the criminal, without successfully defending him against all charges. Thus, "deals" outside of courts are inevitable consequences of the social structure in which the criminal law profession operates and do not necessarily reflect immorality in any of the participants. Nevertheless, this situation facilitates the operations of any participants who happen to be interested in what would generally be regarded as unethical practice.

The research on the jury at the University of Chicago Law School has received much publicity as a consequence of the controversy aroused when judicial permission was received to record secretly the deliberations of juries. Most of the research actually utilized mock trials, based on the public records of actual trials, with experimental juries recruited from actual venire lists. Techniques for recording and analyzing interaction developed in small-group sociology have been applied to analysis of the jury decision-making process. In addition, public opinion polls have been conducted to see how people decide a case after receiving different types of

${ }^{28}$ Wood, Informal Relations in the Practice of Criminal Law, 62 AM. J. Soctolocy 48 (1956). Sce also Newman, Pleading Guilty for Considerations, 46 J. CRIM. L., C. \& P.S. 780 (1956); Ohlin \& Remington, Sentencing Structure: Its Effect Upon Systems for the Administration of Criminal Justice, 23 Law \& Contemp. Prob. 495 (1958). 
instruction from the judge, such as instructions based on the M'Naghten rule ${ }^{29}$ on insanity and instructions based on the Durham decision..$^{30}$ Most of the findings are still to be published. The reports available indicate such things as the greater influence of men than women in determining the jury's verdict; incredible as it may seem, the average male juror talks much more than the average female juror. Also, proprietors and professional people tend to dominate the discussions carried on by occupationally-mixed juries, which may partially compensate for the greater frequency with which they can manage to be excused from jury service. ${ }^{31}$

Five or ten years hence, when the results of current research are more fully reported, we should have several times as much well-validated knowledge on the actual operation of our law enforcement machinery as we now have. This will continue to be a major area of opportunity for sociological research, for there have been little more than conflicting claims and impressions on the facts relevant to proposals for legal reform. New knowledge will raise further issues and call for additional research. Surely, further breakdown of police and judicial resistance to objective study will enhance the possibility of improving our law enforcement and administration machinery.

VI

\section{The Prison as a Social System}

Lloyd E. Ohlin has summarized and analyzed the accomplishments and possibilities of sociological research in prisons so concisely and cogently that it hardly seems appropriate to do more here than reiterate a few of his conclusions. As he puts it: ${ }^{82}$

The penal system ... provides an opportunity for controlled sociological observation and comparative analysis which is very much needed from a practical and theoretical standpoint in criminology. It provides a unique opportunity for sociologists to test sociological theories, and to refine and develop them in the context of the correctional setting.

Unfortunately, the subjects who are so readily available for research because they happen to be incarcerated have been studied primarily to procure information on their life prior to incarceration. The prison itself, a relatively closed social system, has not received the study it merits. Most writing on what goes on in prison is impressionistic, moralistic, superficial, or very obviously biased, rather than systematic, objective, and guided by firmly established behavioral science theory.

The most comprehensive published study of the prison as a social system still is the only published book-length study, Donald Clemmer's The Prison Community. ${ }^{33}$ What Clemmer did, essentially, was to apply the elementary sociological

${ }^{30}$ Cf. M'Naghten's Case, Io Clark \& F. 200, 8 Eng. Rep. 7I8 (H.L. 1843).

${ }^{s 0}$ Durham v. United States, 214 F.2d 862 (D.C. Cir. 1954).

${ }^{31}$ Strodtbeck, James, \& Hawkins, Social Status in Jury Deliberations, 22 Ans. Socrozogrcar Rev. 713 (1957); Strodtbeck \& Mann, Sex Role Differentiation in Jury Deliberations, rg SocromeTRY 3 (1956).

${ }_{32}$ Lloyd E. OHLIN, Soctology ANd the Field of Corrections I2 (1956).

${ }^{23}$ Donard Clemmer, The Prison Community (1940). 
concepts and research techniques of twenty-five years ago to the prison in which he was employed. The result is a picture of the distinctive culture of a prison and of how it is transmitted, as well as a portrayal of prison cliques and classes and their impact on their members.

Sociological publications on prisons since Clemmer have been fragmentary in scope; though often based on longer unpublished theses. One of the most brilliant, that of Richard H. McCleery, won a 1957 national award of the American Political Science Association. McCleery analyzed the relationship between authority and communication in a prison over a ten-year period in which the prison program changed from autocratic repression to democratic retraining. The autocracy was characterized by flow of communication downward only, with power and information in the staff strictly hierarchical. McCleery, Ohlin, and others have shown how, in such a prison, informal organization among inmates achieves some autonomous power by restricting communication between inmates and staff. This tends to prevent sincere involvement of inmates in treatment programs and creates pressure on inmates to conform to the criminal subculture of their fellow convicts. Inmate leadership centers in "old cons" with alleged maximum access to information in the prison. These unofficial inmate leaders achieve more authority and freedom of action than other inmates because advantages are granted to them by custodial personnel, and they, in turn, help get inmates to conform to the major requirements for order and security in the prison. ${ }^{34}$

Democratization of the prison, which was studied by McCleery, involved alteration of communication channels by increasing the size and power of the treatment staff, by encouraging direct communication between inmates and staff, and by granting appreciable influence to an elected inmate council. At first, these changes were followed by some anarchic disorder led initially by former inmate leaders who resented their loss of status and later by "young toughs" no longer kept "in line" by the old cons. Ultimately, stabilization of the prison on the new basis was achieved when inmates and staff were won over to more full support and utilization of the new communication channels.

There is need for more analysis of both prescribed and actual practices in prison, based on systematic study of the expectations maintained by various categories of inmates and employees. L. W. McCorkle and R. R. Korn have called our attention to the way conflicting expectations lead to restriction of output in prison industry; and with Ohlin, they have also indicated the dilemmas encountered by various personnel in corrections. ${ }^{35}$ Modern American sociology has acquired extensive information on

${ }^{34}$ Richard H. McClemry, Policy Change in Prison Management (Michigan State University Political Research Studies No. 5, 1957). See also Schrag, Leadership Among Prison Inmates, ig AM. Socrologicar REv. 37 (1954); Grosser, The Role of Informal Inmate Groups in Change of Values, 5 ChILDReN 25 (1958); Sykes, The Corruption of Authority and Rehabilitation, 34 Sociat Fórciss 257 (1956); Richard McCleery, The Strange Journey (I953); Ohlin \& Lawrence, The Role of the Inmate System in the Institutional Treatment Process, in NAt'z Conf. on Social Welfare, Proceedings (1958) (to be published).

${ }^{35}$ McCorkle \& Korn, Resocialization Within Walls, 293 Annals 88 (1954); Ohlin, The Reduction 
the impact of social-economic class differences on American behavior, but the impact of class background differences on prison social relationships has not been investigated systematically. It has been suggested that change in reference group may be the major factor both in the enculturation of individuals into crime and in their rehabilitation. Richard A. Cloward has vividly demonstrated this enculturation in a military prison. ${ }^{36}$

The limitations of administrators who are not research-oriented were clearly evident in the pronouncements which followed the wave of prison riots in 1952-53. Using the simple rule that anything evil must be caused by everything evil in its setting, all traditional complaints were listed as causes of riots: overcrowding, poorlytrained personnel, inadequate funds, political influence, and so forth. A comparison of state prisons quickly demonstrates that these conditions did not differentiate prisons in which riots occurred from riot-free prisons. Sociologists have suggested explanations in terms of the inmate leadership's loss of advantages in changing prisons and have adduced evidence that discrepancy between precept and practice, rather than poorer conditions, differentiated the riotous from the nonriotous prisons. ${ }^{37}$ Much more theoretical analysis and systematic research is needed in this area, but we shall not enhance knowledge by a mere rehashing of old complaints without investigating their relevance.

Currently, sociologists are engaged in two large-scale research projects on correctional communities, both financed by the Ford Foundation. Under the direction of Professor Lloyd E. Ohlin, of the New York School of Social Work, Columbia University, diverse types of juvenile training schools are being compared in terms of their effects on delinquents, and experimental alterations of their programs are being initiated and evaluated. Also, a four-year program of research on the effectiveness of the federal prison system has been initiated at the University of Illinois under the writer's direction. Several universities, notably Ohio State, Iowa, Wisconsin, and Washington, are sponsoring numerous thesis research programs by sociologists in state prisons. Prospects are that from these efforts will come a much more adequately validated knowledge than we now have on the effects of different types of prison programs on various types of prisoners.

\section{VII}

\section{Prediction Research}

All of the trends in sociological research on corrections cannot be covered here, but before concluding, one type of research of tremendous potential significance for

\footnotetext{
of Role Conficts in Institutional Staff, 5 CHILDREN 65 (1958); Ohlin, Pivin, \& Pappenfort, Major Dilemmas of the Social Worker in Probation and Parole, 2 N.P.P.A.J. 211 (1956).

${ }^{30}$ Richard A. Cloward, Soctal Control and Anomie: A Study of a Military Prison (ig58). See also Helen Wrtmer \& Ruth Kotinsky, New Perśpectives for Research on Juvenile Delineuency (U. S. Children's Bureau, Dep't of Health, Education, and Welfare, Pub. No. 356, 1956).

${ }^{37}$ Hartung \& Floch, A Social Psychological Analysis of Prison Riots: An Hypothesis, 47 J. CRIM. L., C. \& P.S. 51 (1956); Lloyd E. Ohlin, Socrology and the Field of Correctrons 22 (1956).
} 
theory and practice in dealing with crime should be mentioned. This is analysis of the outcome of judicial and correctional decisions in terms of their statistical significance for actuarial prediction.

The comparison of judges and physicians is appropriate whenever judges justify their behavior as crime prevention, rather than as abstract balancing of crime and punishment in fulfilment of transcendental ethical imperatives. The lack of research on the effectiveness of some medical treatments is deplored by physicians, but research on the effectiveness of judicial and correctional prescriptions is like a speck of dust against a mountain when compared with research on the effectiveness of medical prescriptions. In most jurisdictions, a great inconsistency from one judge to the next is known to exist, but its magnitude is seldom objectively tabulated, nor are the long-run consequences of alternative sentencing, classification, and parole policies ever determined in terms of criminal recidivism.

Sociologists, and Sheldon and Eleanor T. Glueck among nonsociologists, ${ }^{38}$ pioneered the type of research design which is needed to provide a scientific basis for judicial and correctional decisions. This is the prediction design. It never will provide with absolute certainty the ideal decision for each offender, no more than medical research permits certain decisions for all cases. Indeed, one should not anticipate achieving in judicial or correctional decisions the average level of predictive certainty achieved in medicine. Certainty in both fields is increased, however, by research which strives for an objective marshaling of relevant experience for each type of case or situation with which a decision-maker may be confronted. Essentially, such research consists of developing the most reliable and predictive procedures possible for classifying criminals (diagnosis), and tabulating the rates of success or failure for alternative treatments of each diagnostic category. In criminology, as in medicine, prediction or "clinical" research is designed in accordance with findings of "basic" research or theory on the causes of the conditions to be treated. Such prediction or clinical research, however, is justified not only for its great practical value, but also as a crucial way of testing many propositions of "pure" science, such as theories of etiology.

The pioneer work of Ernest W. Burgess led to numerous parole and probation prediction studies by sociologists based on analysis of available records. ${ }^{30}$ These undertakings were severely limited by the paucity of data with which they worked, the necessity for restriction of samples to the already selected parolees or probationers, the lack of access to central fingerprint registries for long-run follow-ups on recidivism, and the primitive weighting systems with which the predictive information was combined. A major advance in the scientific basis for judicial decisions

\footnotetext{
${ }^{38}$ See, e.g., Glueck, Predictive Devices and the Individualization of Justice, 23 Law \& Contemp. Prop. 46I (1958).

${ }^{30}$ Schuessler, Parole Prediction: Its History and Status, 45 J. CRuM. L., C. \& P.S. 425 (1954); Garrity, Statistics for Administrative and Policy Decisions, Cal. Youth Authority Q., no. 3, 1957, p. 40; id. no. 4, 1957, p. 33; Lloyd E. Ohzin, Selection for PArole (195x); of. Burgess, Factors Determining Success or Failure On Patole, in Bruce A. Andrew et al., The Workings of the Indetermanate Sentence Law and the Parole Systemi in Illinois 221 (1928).
} 
in the United States will only be possible when information on felony recidivism, now recorded with an adequate completeness by the F.B.I., is made available for criminological research. Elsewhere, the writer has outlined a program for accomplishing this. ${ }^{40}$ In the meantime, the actuarial risk for standard types of decision may be calculated by research in those correctional systems which maintain highly complete records, including postrelease data on felony cases.

The reduction of weeks of calculation to minutes through the use of modern large-scale digital computers should permit development of more rational systems for combining statistical information than that provided by the traditional Burgess and Glueck systems of assigning additive scores to each predictive factor. A shift from additive weighting to multivariate analysis which identifies the most independently predictive clusters of attributes in a criminal may greatly enhance: (I) the accuracy of prediction; (2) the theoretical importance of prediction research for criminology; and (3) the ease with which prediction research findings may be understood and accepted as significant for judicial and correctional policy.

\section{VIII}

\section{Conclusions}

Three general conclusions manifest themselves from our survey of the sociological approach to crime and corrections. These are:

First, sociologists have successfully discredited all purely individualistic explanations for crime. A consequence of the debates of the past is that many of the members of formerly individualistic disciplines now stress cultural influences and interpersonal relations in analyzing the behavior of criminals and delinquents. Some of the best sociology now is being developed by psychologists and psychiatrists, in criminology and in other fields. This trend is likely to grow as the boundaries between sociology, psychology, anthropology, political science, psychiatry, and psychoanalysis become more loose (as have the boundaries between chemistry, physics, and the biological sciences).

Secondly, developments in the study of crime and corrections follow, but lag somewhat behind, developments in general behavioral science theory and research. Major contributions to criminology are those which markedly reduce this lag. Good criminology is good behavioral science; poor criminology reflects poor behavioral science.

Thirdly, there has been continuing interaction and cross-fertilization between the abstract explanation for crime and the analysis and evaluation of correction and crime-prevention programs. Any judicial or correctional policy which is based on a seriously invalid conception of the behavior of the persons whom it involves is likely to do much more damage than benefit. Any judicial or correctional policy which is not modified on the basis of significant advances in behavioral science is

${ }^{\circ}$ Glaser, Released Offender Statistics: A Proposal for a National Program, 19 AM. J. Correction I5 (1957); Criminal Career Statistics, in AM. CoRrectional Ass'n, Proceedngs ro3 (I957). 
likely to stagnate or deteriorate. The prospect of a rapid increase in applied research in the courts and in correction, as well as in noncriminological areas of social research, means that abstract criminology is likely to be refined and sharpened a great deal in the decades ahead. It will be difficult, but it will be important, that all of us keep up with new developments. 